\title{
COUPLING OF DIfFUSION FLAME STRUCTURE TO AN UNSTEADY \\ VORTICAL FLOWFIELD
}

C.J. Mueller and R.W. Schefer

Combustion Research Facility

Sandia National Laboratories

Livermore, CA 94551-0969

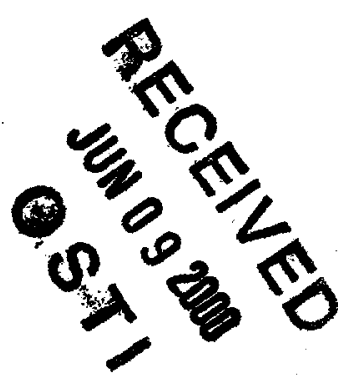

The subraitted manuscript has been anthored by a contractor of the Untise States Govermment under contract. Accordingly the United States Gov ernment retains a non-exciusive, royalty-free license to publish or re. produce the published form of this contribution, or allow others to do yo, for United States Government puxpooser.

Paper submitted to the 27th International Symposium on Combustion

University of Colorado, Boulder, CO.

August 2-7,1998.

Word Length: Text: 3540, Figures: 1960.

Total: 5500

Presentation preference: Oral presentation.

Colloquim preference: Turbulent Non-Premixed Combustion 


\section{DISCLAIMER}

This report was prepared as an account of work sponsored by an agency of the United States Government. Neither the United States Government nor any agency thereof, nor any of their employees, make any warranty, express or implied, or assumes any legal liability or responsibility for the accuracy, completeness, or usefulness of any information, apparatus, product, or process disclosed, or represents that its use would not infringe privately owned rights. Reference herein to any specific commercial product, process, or service by trade name, trademark, manufacturer, or otherwise does not necessarily constitute or imply its endorsement, recommendation, or favoring by the United States Government or any agency thereof. The views and opinions of authors expressed herein do not necessarily state or reflect those of the United States Government or any agency thereof. 


\section{DISCLAIMER}

Portions of this document may be illegible in electronic image products. Images are produced from the best available original document. 


\begin{abstract}
A laminar methane-air diffusion flame is interacted with vortices of various sizes and strengths in order to better understand unsteady stretch and history effects on turbulent flames. The nitrogendiluted fuel stream of a Wolfhard-Parker slot burner is acoustically forced, producing repeatable two-dimensional vortices that strain and curve the flame. Phase locked, planar laser-induced fluorescence (PLIF) diagnostics are used to quantify the response of the OH-radical to the vortexinduced stretch. Acetone PLIF images are used to clarify the relationship between the vortex structure and the flame. The results show that the vortex causes significant variations in the $\mathrm{OH}$ layer thickness. In particular, negative strain produces a doubling of the flame thickness. Such large increases in $\mathrm{OH}$ layer thickness are not predicted by the laminar flamelet model (LFM) because negative strain rates cannot be simulated using standard counterflow flamelet geometry. Local extinction of the $\mathrm{OH}$ layer due to high strain is observed near the flame base. Peak $\mathrm{OH}$ mole fraction levels vary considerably more than adiabatic LFM predictions. In particular, the peak $\mathrm{OH}$ decreases by a factor of two with downstream distance. This decrease is believed due to dilution of reactants by combustion products formed elsewhere in the flow. A simplified model is proposed, which shows the $\mathrm{OH}$ concentration is sensitive to product dilution through the scalar dissipation rate.
\end{abstract}




\section{INTRODUCTION}

Numerical simulations of turbulent reacting flows are currently limited by excessive computational requirements imposed by the calculation of detailed flame chemistry. One approach is to use simplifying assumptions and empirical models to reduce the number of equations and to close the equations. Another approach is to use a Laminar Flamelet Model (LFM), which allows flame chemistry to be effectively decoupled from local flowfield properties.

The LFM is based on a steady, one-dimensional counterflow diffusion flame configuration [1]. An important question is the applicability of the LFM to turbulent flames where unsteadiness, threedimensionality and flowfield history effects are important. Direct numerical simulations of a vortex pair interacting with a planar flame were recently used to evaluate the validity limits of the LFM in diffusion flames [2]. It was found that the domain of applicability is limited by 1) unsteady flow effects in which the time response of the flame chemistry/structure is insufficient to adjust to rapidly changing flow conditions, 2) flame curvature effects in which one-dimensionality of the flame structure is not maintained, and 3) quenching of flame chemistry in which local stretch rates exceed limiting values and the flame is extinguished.

The interaction of a single toroidal vortex with laminar premixed propane-air flames under fuel lean conditions has been the subject of several studies. Local flame quenching due to high induced stretch was confirmed and the effect of flame curvature on $\mathrm{OH}$ levels was quantified [3]. The importance of accounting for flow unsteadiness in counterflow simulations was also verified [4]. Vortex/flame interactions have been investigated in forced laminar, axisymmetric $\mathrm{CH}_{4}$ diffusion flames [5,6]. High strain rates generated by the vortices resulted in local extinction of the flame. A numerical model based on infinitely fast chemistry successfully predicted the formation of the forced vortex pairs [6]. However, due to the assumption of infinitely fast chemistry, the model did not predict the observed quenching, indicating the necessity of a more realistic finite-rate chemistry model.

The objective of the present investigation is to characterize the fundamental interaction of a vortex with a diffusion flame. These measurements are carried out in a planar, laminar $\mathrm{CH}_{4}$-jet flame with acoustic forcing. In particular, the effects of curvature, unsteadiness, and high local stretch/scalar dissipation rates leading to flame quenching will be examined using OH PLIF for flame visualization and acetone PLIF to characterize vortex structure. Comparisons of quantitative $\mathrm{OH}$ 
data with laminar flamelet calculations will be made to help assess the validity of the LFM in the present flow.

\section{EXPERIMENTAL SYSTEM}

\section{Burner Description and Flow Conditions}

The laminar flame was stabilized on a Wolfhard-Parker slot burner similar to that used by Smyth et al. [7]. The burner consists of a rectangular slot $11-\mathrm{mm}$ wide by $80-\mathrm{mm}$ long for the fuel flow, bounded on the two long sides by lower-velocity coflowing air streams. A honeycomb section and fine-wire screen upstream of the fuel-slot opening provide a uniform laminar flow. The test section is a $150-\mathrm{mm}$ square chamber. In addition to the enclosure, a wire mesh forming a contraction near the top of the burner was used to suppress flame flicker The burner provides a reproducible, twodimensional flame with two identical flame sheets located in the laminar mixing layers adjacent to the fuel jet. Narrow slots located on opposite sides of the chamber allow the laser sheet to pass through the burner orthogonal to the flame sheets while fused-silica windows in the walls of the enclosure provide access for the detection optics.

The fuel jet was acoustically forced by two $100-\mathrm{mm}$ diameter loudspeakers attached to the walls of the fuel-jet duct upstream of the burner. The speakers were driven by a function generator with adjustable frequency and amplitude. The laser is run continuously at $7.5 \mathrm{~Hz}$ by a pulse generator while the speaker driver is continuous at the selected driving frequency. A variable-delay pulse generator controls the phase of the speaker voltage relative to the laser pulse.

The fuel mixture was methane diluted with $66 \%$ (by volume) nitrogen to reduce soot formation. A fuel-jet velocity of $0.66 \mathrm{~m} / \mathrm{s}$ and a coflowing-air velocity of $0.19 \mathrm{~m} / \mathrm{s}$ provided a stable flame over a range of forcing frequencies and amplitudes. Two modes of flame behavior were observed. These are 1) a low frequency mode (below $25 \mathrm{~Hz}$ ) characterized by reproducible, periodic flame lifting and reattachment, and 2) a high frequency mode (above $70 \mathrm{~Hz}$ ) characterized by an always-lifted flame base and local flame extinction. At intermediate frequencies the flame base is randomly attached and lifted from the fuel nozzle. Interactions at 7.5 and $90 \mathrm{~Hz}$ provided a good representation of low frequency and high frequency behaviors. At the $7.5 \mathrm{~Hz}$ frequency, the voltage pulse to the amplifier/speaker consisted of a fast $(<1 \mathrm{msec})$ rise-time followed by a 33 msec exponential decay, which resulted in a rapid rise in the fuel-jet centerline velocity to $1.2 \mathrm{~m} / \mathrm{s}$ and subsequent return to $0.66 \mathrm{~m} / \mathrm{s}$ over a total time of $13 \mathrm{msec}$. At the $90 \mathrm{~Hz}$ frequency, a square wave driving pulse resulted in a nearly sinusoidal variation in the centerline fuel velocity (maximum value $1.5 \mathrm{~m} / \mathrm{s}$; mimimum value $0.0 \mathrm{~m} / \mathrm{s}$ ). 


\section{Fluorescence Imaging System}

The ultraviolet laser radiation for $\mathrm{OH}$ molecule excitation was provided by a Nd:YAG-pumped dye laser. The beam was used to pump the $\mathrm{Q}_{1}(6)$ line of the $(1,0)$ band of the $\mathrm{OH}^{2} \Sigma-\mathrm{X}^{2} \mathrm{II}$ electronic transition at $282.928 \mathrm{~nm}$. The $\mathrm{OH}$ fluorescence signal was collected using a $105-\mathrm{mm}$ focal length, f/4.5 UV Nikkor lens, filtered (Schott WG305 colored glass), and focused onto an intensified CCD camera. The intensifier was gated for $2 \mu \mathrm{s}$ to minimize flame luminescence and background light. The camera was operated in a 576x384 pixel format, providing a spatial resolution of $100 \mu \mathrm{m}$ per pixel.

The collimated laser sheet ( $200 \mu \mathrm{m}$ thick) was formed by a cylindrical/spherical lens combination. An aperture at the entrance slot to the burner passed only the middle $33 \%$ of the sheet into the burner, thus reducing variations in laser power across the sheet to less than $20 \%$. A laser power below $7 \mathrm{~mJ} /$ pulse provided an average spectral power density in the linear fluorescence regime. Each $\mathrm{OH}$ image was normalized by the measured laser sheet intensity distribution and corrected for variations in pulse energy on a shot-by-shot basis. Previous strained laminar flame calculations were used to estimate the errors due to variations in fluorescence quenching and ground state population fraction for nitrogen-diluted methane flames [8]. At low values of strain, the combined corrections due to quenching and population fraction variations across the flame were less than $5 \%$ of the maximum $\mathrm{OH}$ concentration. At strain rates approaching extinction, the corrections were less than $20 \%$. These estimates are indicative of errors in the present measurements.

Laser-induced fluorescence of acetone was used as a fuel tracer. Acetone was seeded directly into the fuel flow using an aerosol generator. The same laser excitation wavelength of $282.928 \mathrm{~nm}$ was used to excite fluorescence from the acetone. Since the fluorescence signal from acetone is largely independent of collisional environment, the signal is proportional to acetone number density [9]. However, acetone rapidly pyrolizes at temperatures above $1200 \mathrm{~K}$, so while the acetone images are useful to identify the vortical structure and location, they do not provide a quantitative representation of fuel concentration.

\section{RESULTS}

Six representative, single-shot $\mathrm{OH}$ images showing the time development of the flame/vortex interaction are presented in Fig. 1 for the $7.5 \mathrm{~Hz}$ forcing frequency. The images show thinning and thickening of the $\mathrm{OH}$ layer as the vortex moves through the field of view. The image for time $t=0$ corresponds to an unforced flame prior to the influence of the vortex, when the flame is nearly 
straight in the vertical direction and located along the interface separating the fuel and coflow air. The flame thickness, based on the $\mathrm{OH}$ profile, varies between 1 and $1.6 \mathrm{~mm}$ (using the $50 \%$ of maximum points).

Calculations have shown that positive strain rates exist in the region around the outer, downstream edge of the vortex and negative strain rates exist in the highly-curved region at the upstream edge of the vortex where the flame appears folded [10]. The images show that positive strain rates result in $\mathrm{OH}$ layer thinning while negative strain rates cause significant thickening. In negative-strain regions, the thickness of the $\mathrm{OH}$ layer increases with time, reaching a maximum value of nearly $4 \mathrm{~mm}$ in the last image at time $t=66.7 \mathrm{~ms}$. In the positively-strained region along the outer vortex edge, the $\mathrm{OH}$ layer thickness is nearly constant at $0.75 \mathrm{~mm}(+/-10 \%)$ over the sequence of images shown. The degree of flame wrinkling reaches a maximum value at time $t=33.3 \mathrm{~ms}$ as the flame becomes more completely wrapped around the vortex.

The flame base is observed to periodically lift from the burner lip as the vortex passes along the flame. The liftoff height increases to a maximum of $5 \mathrm{~mm}$ before moving back upstream to reattach as the vortex continues downstream. We speculate that this sudden lifoff is due to acceleration of the streamwise velocity component at the flame base as the vortex passes. Particle image velocimetry (PIV) data is currently being obtained to verify this observation.

Figure 2 shows six representatve images at the $90 \mathrm{~Hz}$ frequency. In this case, the flame remains lifted at a constant height of about $5 \mathrm{~mm}$. The constant liftoff height is due to the higher forcing frequency, which results in a close vortex spacing that precludes flame reattachment. Most notable in Fig. 2 is the strain-induced extinction of the $\mathrm{OH}$ layer along the upstream vortex edge. At time $\mathrm{t}=0$, the $\mathrm{OH}$ layer thickness is nearly constant along the upstream trailing edge of the vortex. During the next two images the $\mathrm{OH}$ layer is stretched and thinned until at $\mathrm{t}=2.8 \mathrm{~ms}$ a break occurs where the $\mathrm{OH}$ layer is thinnest. This event results in the formation of a separated island of $\mathrm{OH}$ which burns out during the next $6 \mathrm{~ms}$.

Further details of the $\mathrm{OH}$ island formation are presented in Fig. 3 where the fuel stream has been doped with acetone. The acetone reveals the presence of two fuel-side vortices that cause local extinction of the $\mathrm{OH}$ layer. One vortex, located above the rolled-up portion the flame, is larger and accounts for the large curvature produced as the $\mathrm{OH}$ layer wraps around it. Its rotational direction is clockwise. A second vortex, located upstream of the flame, is smaller and again has a clockwise rotation. It also has a higher speed and thus moves closer to the downstream vortex during the sequence. The upstream tail of the flame undergoes significant positive strain due to the vortex- 
induced rotational motion, becomes significantly thinner where the distance between vortices is minimum and, finally, is quenched due to the high strain. The $\mathrm{OH}$ island is formed as a result of this quenching. The upstream vortex now replaces the previous vortex as the vortex around which the flame is stabilized and the interaction repeats.

\section{DISCUSSION}

Figure 4 shows the variation in $\mathrm{OH}$ layer thickness and peak $\mathrm{OH}$ along the distance tangential to the flame for the unperturbed flame. The coordinate origin is located at the flame base. The peak $\mathrm{OH}$ mole fraction is normalized by the peak $\mathrm{OH}$ value near the base of the unperturbed flame. Figure 5 shows corresponding results for a perturbed flame at a forcing frequency of $7.5 \mathrm{~Hz}$ and time $\mathrm{t}=18.5 \mathrm{~ms}$. In the unperturbed flame, the $\mathrm{OH}$ layer thickness increases monotonically with downstream distance, while the peak $\mathrm{OH}$ value decreases by nearly a factor of two. The perturbed flame shows a rapid initial rise in the $\mathrm{OH}$ layer thickness over the first $4 \mathrm{~mm}$ of flame length. The peak value of $2.5 \mathrm{~mm}$ occurs in the negative strain region at the upstream vortex edge. The $\mathrm{OH}$ layer thickness decreases in the region of positive stretch along the outer vortex edge to a minimum value of $0.75 \mathrm{~mm}$, before increasing again to about $2 \mathrm{~mm}$ downstream of the vortex.

These large variations in $\mathrm{OH}$ thickness in the perturbed flame can be contrasted with a nearly linear decrease in the peak $\mathrm{OH}$ mole fraction over the same coordinate range. A comparison with the peak $\mathrm{OH}$ variation along the unperturbed flame in Fig. 4 shows nearly identical slopes. This comparison indicates that the varying strain and curvature along the vortex, while significantly affecting the $\mathrm{OH}$ layer thickness, has a minimal effect on peak $\mathrm{OH}$. This observation is further substantiated by Fig. 6 where the peak $\mathrm{OH}$ mole fraction is plotted as a function of the $\mathrm{OH}$ layer thickness for the $7.5 \mathrm{~Hz}$ forcing frequency. Data points are included for all six times seen in Fig. 1. The symbol's color indicates relative distance downstream. The results show that the $\mathrm{OH}$ concentration is primarily determined by downstream distance and is largely uncorrelated with flame thickness. Note that results for the $90 \mathrm{~Hz}$ forcing frequency (not shown) are consistent with the lower frequency results in Fig. 6.

The downstream decrease in peak $\mathrm{OH}$ is surprising since one might expect that the peak $\mathrm{OH}$ mole fraction in the unperturbed flame would be relatively constant in the upstream region where the images were taken. That is, provided the strain or, equivalently, the scalar dissipation is nearly constant, the LFM requires that the flame structure is fixed and the peak OH remains constant. Three mechanisms were considered that might account for the decrease in maximum $\mathrm{OH}: 1$ ) removal of $\mathrm{OH}$ through reactions with soot or soot precursors, 2) variations in strain or scalar 
dissipation with downstream distance and 3) changes in mixture composition and/or temperature with downstream distance.

Comparable decreases in $\mathrm{OH}$ have been measured in laminar methane-air diffusion flames [11]. The decrease was attributed to reactions between $\mathrm{OH}$ and soot. To test this possibility, the decrease in peak $\mathrm{OH}$ with downstream distance was measured with additional fuel dilutions of $50 \%$ and $76 \% \mathrm{~N}_{2}$. These results are shown for comparison with the nominal $66 \% \mathrm{~N}_{2}$ dilution results in Fig. 4b. Although increased $\mathrm{N}_{2}$ dilution caused a noticeable reduction in visible soot, over the range of dilutions studied there is at most a $15 \%$ reduction in peak (absolute) $\mathrm{OH}$ mole fraction. More importantly, the rates of decrease are nearly identical for the three dilution levels, even though the visible soot formation rate is delayed by increased dilution. Thus, reactions with soot do not account for the disappearance of $\mathrm{OH}$.

The effect of variable strain/scalar dissipation was considered next. Figure 4a shows an increase in the $\mathrm{OH}$ layer thickness with downstream distance in the unperturbed flame. This is likely accompanied by an increase in the width of the mixed interface between the fuel and air streams due to interdiffusion of fuel, oxidizer, and products. With this increased layer thickness a decrease in mixture fraction gradient and scalar dissipation would be expected. Similarly, the shear layer located between the high velocity fuel jet and the coflow air contains a velocity gradient that decreases with downstream distance. Thus strain rates at the flame surface should also decrease with downstream distance. Using the numerical model and code developed elsewhere [12], counterflow diffusion flame calculations were carried out over a range of strain rates, and thus scalar dissipation rates, to determine the dependency of the maximum $\mathrm{OH}$ level on these parameters. The calculations considered a fuel stream consisting of methane diluted with $66 \% \mathrm{~N}_{2}$ and an opposing air stream. A kinetic mechanism considering $\mathrm{C}_{2}$ hydrocarbons was used [13].

The solid line in Fig. 6 (0\% product dilution) indicates calculated results for strain rates from near extinction (left end of the curve) to well below extinction (right end). The lowest strain rate used was $30 \mathrm{sec}^{-1}$, which is comparable with strain rates measured recently by the authors in the unperturbed flame using PIV. Significant departures from the calculations are seen. Negative strain regions, in particular, exhibit large increases in flame thickness, well beyond the predictions for the minimum strain rate used. Such large increases in $\mathrm{OH}$ layer thickness are not predicted by the model because negative strain rates cannot be simulated using standard counterflow flamelet geometry. The observed peak $\mathrm{OH}$ mole fractions also vary considerably more than the predictions. With the exception of strain rates approaching extinction, which are considerably higher than strain 
rates in the present flame, changes in strain cannot account for more than a $10 \%$ change in $\mathrm{OH}$ concentration. Thus, variations in strain also cannot account for the observed $\mathrm{OH}$ variation.

A third possible cause for the $\mathrm{OH}$ decrease is dilution of the fuel and air by combustion products. This is essentially a history effect in which $\mathrm{OH}$ production and removal kinetics are affected by events that occur elsewhere in the flow. In the present configuration, the flow direction of both fuel and oxidizer streams is parallel to the flame surface. This contrasts with a counterflow diffusion flame where combustion products formed in the reaction zone are carried away from the flame zone, perpendicular to the incoming reactant streams. In the coflowing reactant stream configuration, products formed in the upstream reaction zone are convected downstream, parallel to the flame surface. This promotes dilution of the reactants by product species, which could alter the $\mathrm{OH}$ chemistry.

The effect of dilution by product species was investigated by adding varying amounts of product dilution to the reactants and repeating the counterflow diffusion flame calculations. The product mixture was assumed to consist of major species $\left(\mathrm{H}_{2} \mathrm{O}, \mathrm{CO}, \mathrm{CO}_{2}\right.$, and $\left.\mathrm{O}_{2}\right)$ with a composition and temperature corresponding to stoichiometric conditions in a low strain flame. The addition of up to $50 \%$ by volume of product mixture to both the fuel and air streams was considered. The dashed curve in Fig. 6 shows the results for $50 \%$ product dilution. Note the temperature of the reactant mixture increases due to the addition of high temperature products. Results are shown for adiabatic mixing (dashed line), and mixing with $10 \%$ heat loss (dotted line), which resulted in reactant-mixture inlet temperatures of $1070 \mathrm{~K}$ and $956 \mathrm{~K}$, respectively. The net result of product dilution is a significant reduction in the predicted $\mathrm{OH}$ level. Examination of the scalar dissipation rate at the stoichiometric mixture fraction shows that product dilution significantly reduces the scalar dissipation rate: for a given strain rate the scalar dissipation is reduced by a factor of 5 with $50 \%$ product dilution. Thus, flame structure and $\mathrm{OH}$ concentration are sensitive to product dilution through the scalar dissipation rate. Further, when a reasonable estimate of heat losses during mixing of reactants and combustion products is included, predicted results are consistent with observed variations in $\mathrm{X}_{\mathrm{OH}} / \mathrm{X}_{\mathrm{OH}, \mathrm{ref}}$.

These results illustrate the importance of multidimensional effects on flame structure. The LFM is one dimensional and considers only a reactive-convective balance normal to the flame. In the present geometry, convective flow parallel to the flame is significant and could be expected to cause significant departures from counter flow diffusion flame structure. For example, significant differences between LFM predictions and measured temperature profiles in laminar diffusion flames with coflowing air, which were attributed to multidimensional effects [14]. Ashurst and 
Williams [10] also noted the importance of transverse convection on flame properties during flame/vortex interactions where significant gradients are established parallel to the flame surface.

\section{SUMMARY AND CONCLUSIONS}

A laminar methane-air diffusion flame is interacted with fuel-side vortices of selected sizes and strengths in order to better understand unsteady stretch and history effects on turbulent flames. Repeatable, two-dimensional vortices that strain and curve the flame are produced by forcing the fuel stream of a Wolfhard-Parker slot burner using loudspeakers. Forcing frequencies of 7.5 and $90 \mathrm{~Hz}$ were studied in detail using $\mathrm{OH}$ and acetone PLIF. Significant thinning and thickening of the $\mathrm{OH}$ layer occurs at both forcing frequencies as the vortex moves along the flame. For the $7.5 \mathrm{~Hz}$ case, positive strain rates result in thinning of the $\mathrm{OH}$ layer by up to $50 \%$, while negative strain rates cause as much as a $100 \%$ thickening of the $\mathrm{OH}$ layer. Such large increases in $\mathrm{OH}$ layer thickness cannot be modeled using counterflow flamelet computations, and thus are not predicted by the LFM. Strain-induced extinction of the $\mathrm{OH}$ layer is also observed near the flame base in the $90 \mathrm{~Hz}$ case, where acetone images reveal two fuel-side vortices that induce positive strain on the flame. This high strain leads to a break in the $\mathrm{OH}$ layer and the formation of an island of $\mathrm{OH}$.

The peak $\mathrm{OH}$ mole fraction decreases by nearly a factor of two with downstream distance in the upstream region of the unperturbed flame. Three mechanisms were considered that might account for the observed decrease. Reactions with soot cannot account for the decrease since the $\mathrm{OH}$ variation was insensitive to increased $\mathrm{N}_{2}$ dilution, even though visible soot formation was reduced. Counterflow diffusion flame calculations showed that variations in strain rate cannot account for more than a $10 \%$ change in maximum $\mathrm{OH}$. A third possible cause for the $\mathrm{OH}$ decrease is dilution of the fuel and air by combustion products. In the coflowing reactant stream configuration, products formed in the reaction zone at upstream locations are convected downstream, parallel to the flame surface. This promotes dilution of the reactants by product species, which could alter the $\mathrm{OH}$ chemistry. A simplified model to account for reactant dilution by products, in which both the fuel and air inlet streams are diluted by up to $50 \%$ with high temperature product species, showed decreases in $\mathrm{OH}$ levels comparable with experimental observations. Product dilution was found to reduce the scalar dissipation rate at the stoichiometric mixture fraction. Thus, $\mathrm{OH}$ concentrations are particularly sensitive to product dilution through the scalar dissipation rate.

\section{Acknowledgments}


This research was supported by the United States Department of Energy, Office of Basic Energy Sciences, Division of Chemical Sciences.

\section{REFERENCES}

1. Tsuji, H., Prog. Energy Combust. Sci. 8:93-119 (1982).

2. Cuenot, B. and Poinsot, T., Twenty Fifth Symposium (International) on Combustion, The Combustion Institute, Pittsburgh, 1994, p. 1383.

3. Roberts, W. L., Driscoll, J. F., Drake, M. C. and Ratcliffe, J. W., Twenty Fourth Symposium (International) on Combustion, The Combustion Institute, Pittsburgh, 1992, p. 169.

4. Mueller, C. J., Driscoll, J. F., Sutkus, D. J., Roberts, W. L., Drake, M. C. and Smooke, M. D., Comb. Flame 100:323-331 (1995).

5. Lewis, G. S., Cantwell, B. J., Vandsburger, U. and Bowman, C. T., Twenty Second Symposium (International) on Combustion, The Combustion Institute, Pittsburgh, 1988, p. 515.

6. Hsu, K. Y., Chen, L. D., Katta, V. R., Goss, L. P. and Roquemore, W. M., AIAA Paper 93-0455, 1993.

7. Smyth, K. C., Tjossem, P. J. H., Hamins, A. and Miller, J. H., Combust. Flame 79:366-380 (1990).

8. Barlow, R. S. and Collignon, A., AIAA Paper 91-0179, 1991.

9. Clemens, N. T. and Paul, P. H.,Comb. Flame 102:271-284 (1995).

10. Ashurst, W. T. and Williams, F. A., Twenty Third Symposium (International) on Combustion, The Combustion Institute, Pittsburgh, 1990, p. 543.

11. Garo, A., Prado, G. and Lahaye, J., Comb. Flame 79:226-233 (1990).

12. Lutz, A. E., Kee, R. J., Grcar, J. F. and Rupley, F. M., Sandia National Laboratories Report No. SAND-8243, May, 1996.

13. Frenklach, M., Wang, W. C., Goldenberg, M., Smith, G. P., Golden, D. M., Hanson, R. K., Gardiner, W. C. and Lissianski, V., GRI Report No. GRI-95/0058, November 1, 1995.

14. Smooke, M. D., Xu, Y., Zurn, R. M., Lin, P., Frank, J. H. and Long, M. B., Twenty Fourth Symposium (International) on Combustion, The Combustion Institute, Pittsburgh, 1992, p. 813. 


\section{Figure Captions}

Fig. 1. Time sequence of OH PLIF images at $7.5 \mathrm{~Hz}$ forcing frequency. Each image covers a field-of-view of $29.3 \mathrm{~mm}$ in the horizontal direction by $34.9 \mathrm{~mm}$ in the vertical, with only the right side of the flame shown. Times increments are from instant of first noticable flame perturbation by vortex. Upper left image is defined as $t=0$.

Fig. 2. Time sequence of OH PLIF images at $90 \mathrm{~Hz}$ forcing frequency.

Fig. 3. Combined OH/acetone PLIF images showing mechanism of local extinction $(90 \mathrm{~Hz}$ forcing).

Fig. 4. Variation of (a) $\mathrm{OH}$ layer thickness and (b) peak $\mathrm{OH}$ mole fraction with tangential distance in unforced flames. Peak $\mathrm{OH}$ mole fraction variation is shown for dilutions of $50 \%$ (circles), $66 \%$ (squares), and $75 \%$ (triangles) $\mathrm{N}_{2}$ by volume. Coordinate origin corresponds to flame base.

Fig. 5. Variation of (a) $\mathrm{OH}$ layer thickness and (b) peak $\mathrm{OH}$ mole fraction with tangential coordinate for $7.5 \mathrm{~Hz}$ forcing case, corresponding to $t=18.5 \mathrm{~ms}$ image in Fig. 2

Fig. 6. Peak $\mathrm{OH}$ mole fraction vs. $\mathrm{OH}$ layer thickness for $7.5 \mathrm{~Hz}$ forcing. Measurements are indicated by symbols. The symbol's color indicates relative distance downstream (bluish symbols represent data from upstream locations whereas red symbols represent data from downstream locations). Counterflow diffusion flame model predictions are shown for no product dilution (solid line), 50\% product dilution with adiabatic mixing (dashed line), and 50\% product dilution with $10 \%$ heat loss (dotted line). Reactant inlet temperature was $300 \mathrm{~K}$ for no product dilution. 

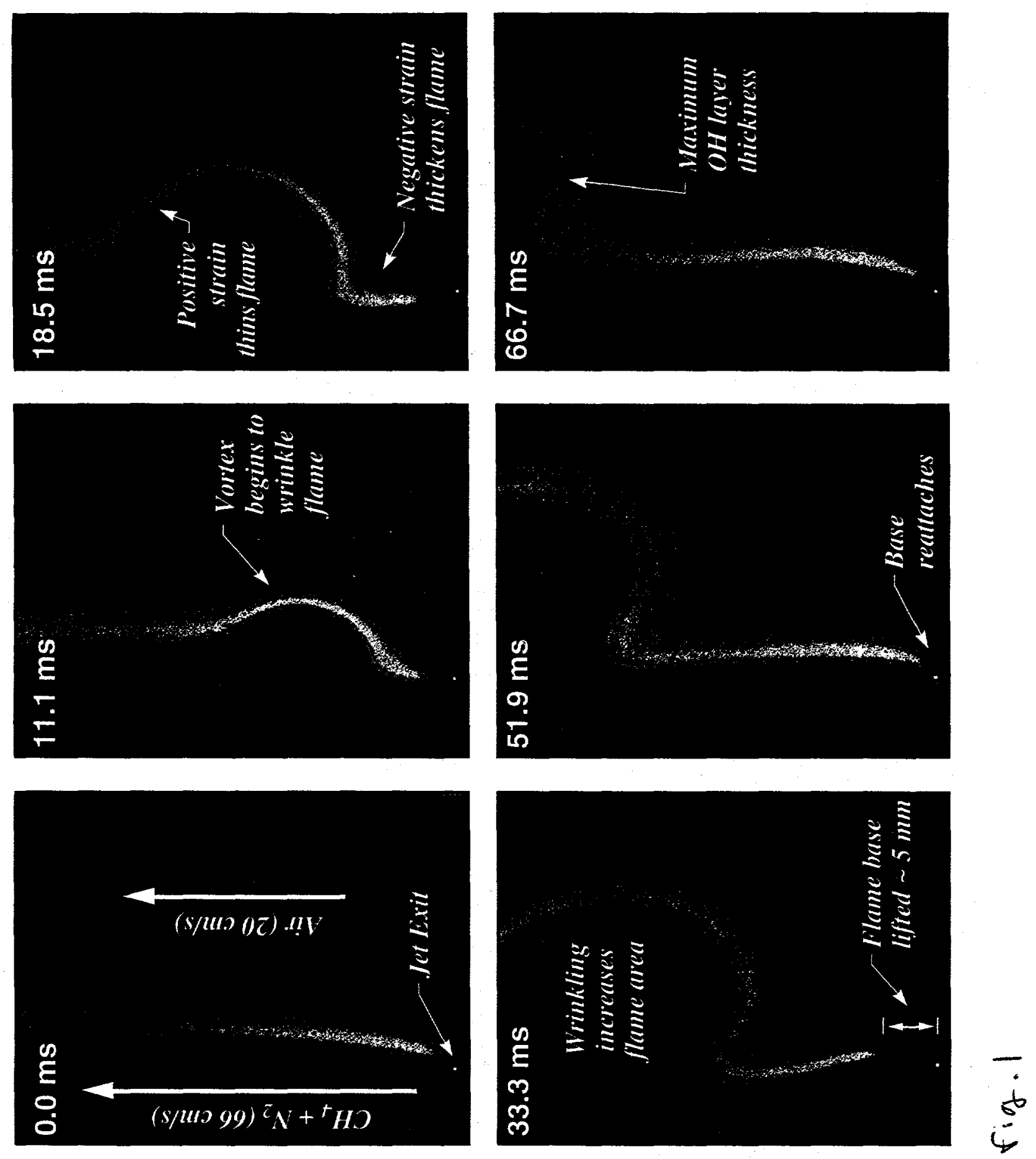

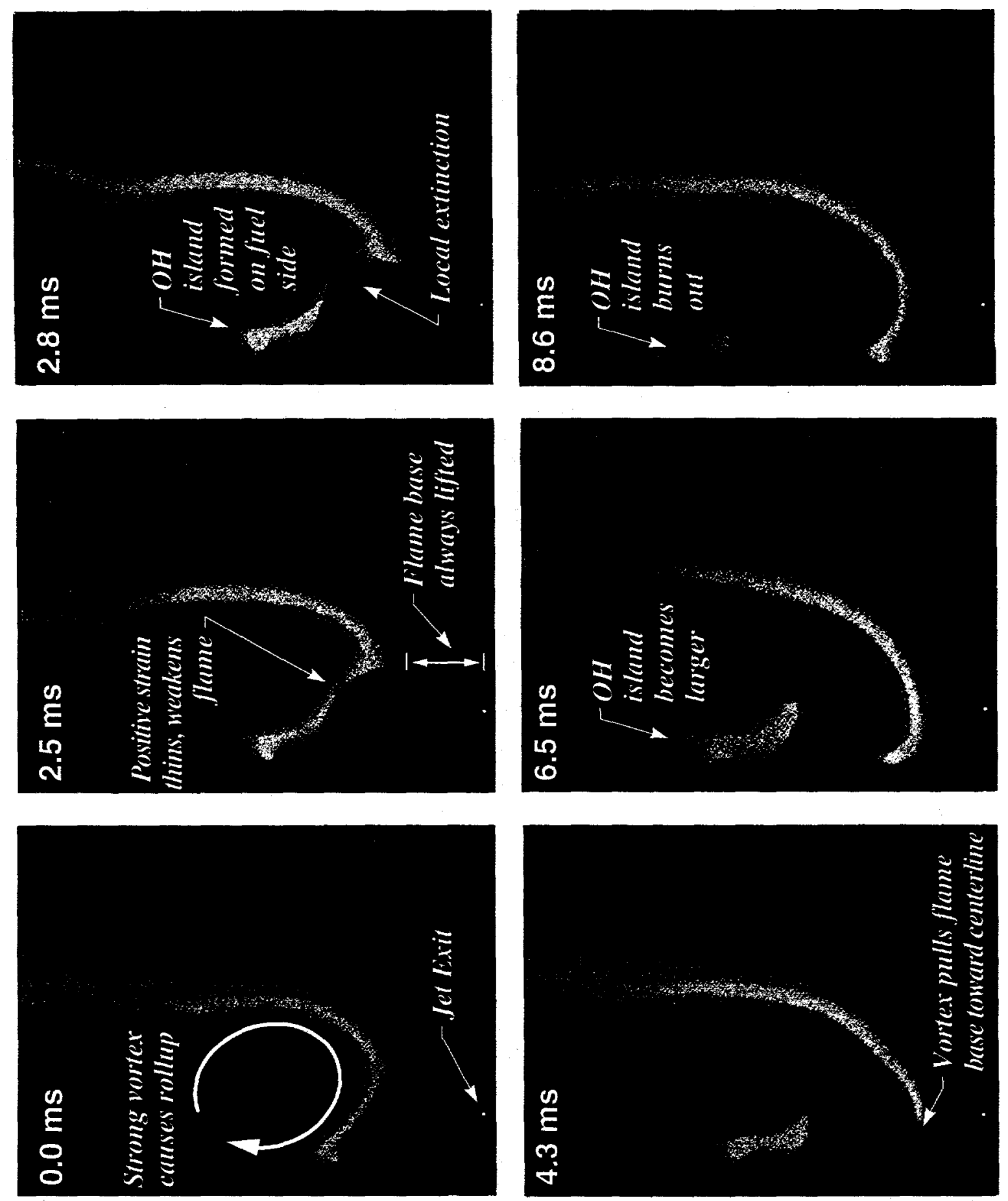

$\frac{1}{5}$ 

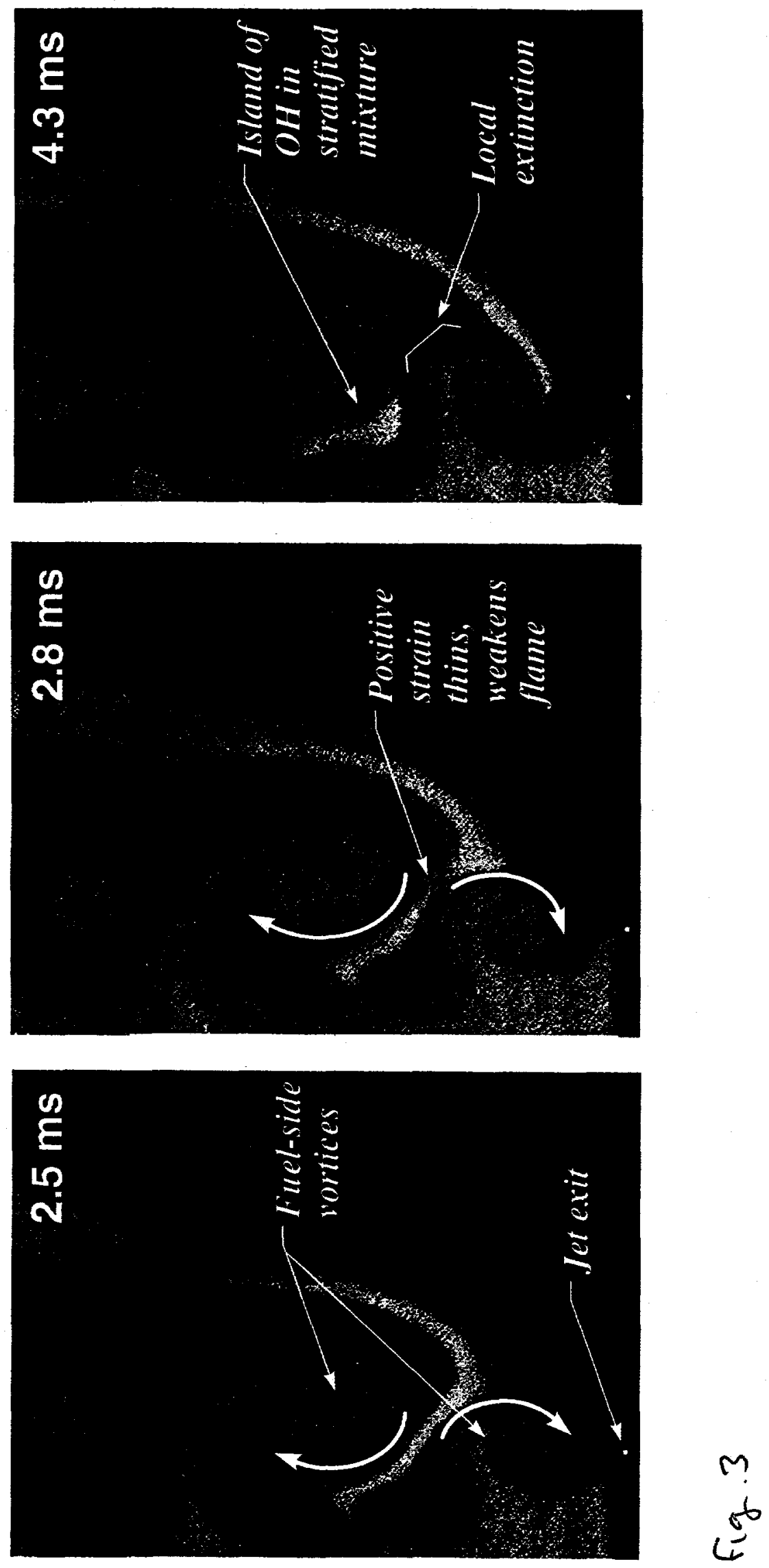


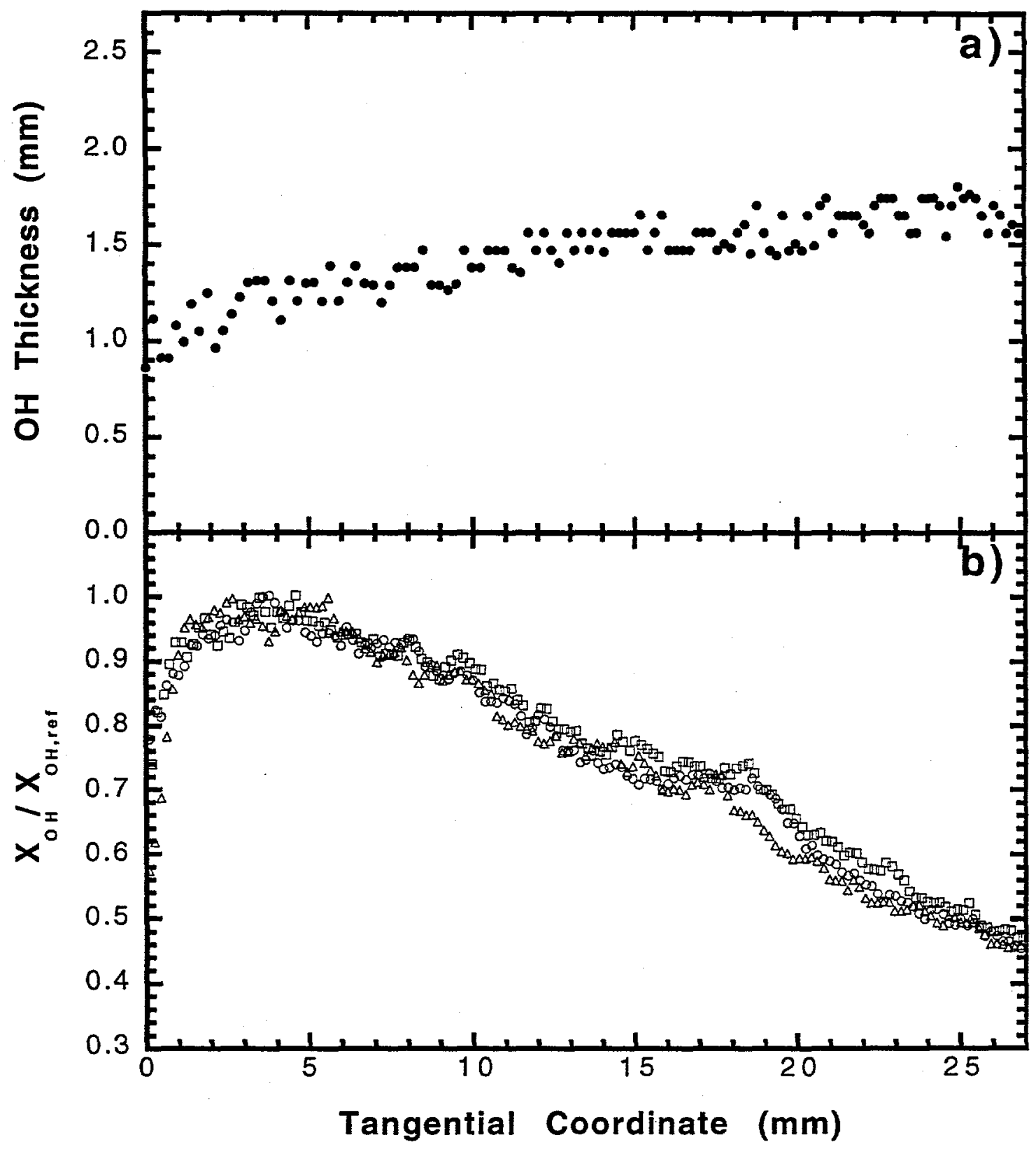

Fig. 4 


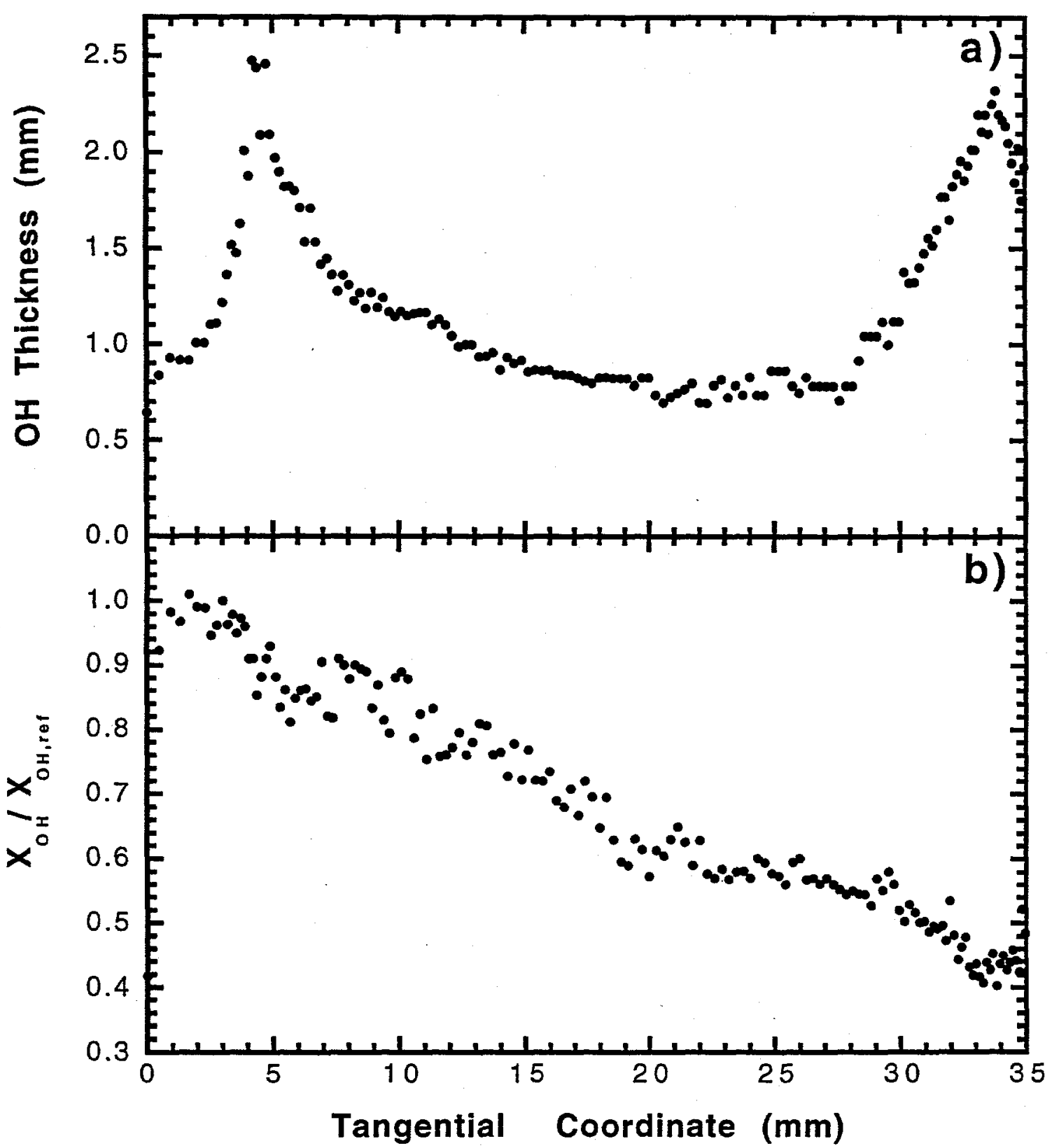

fig. 5 

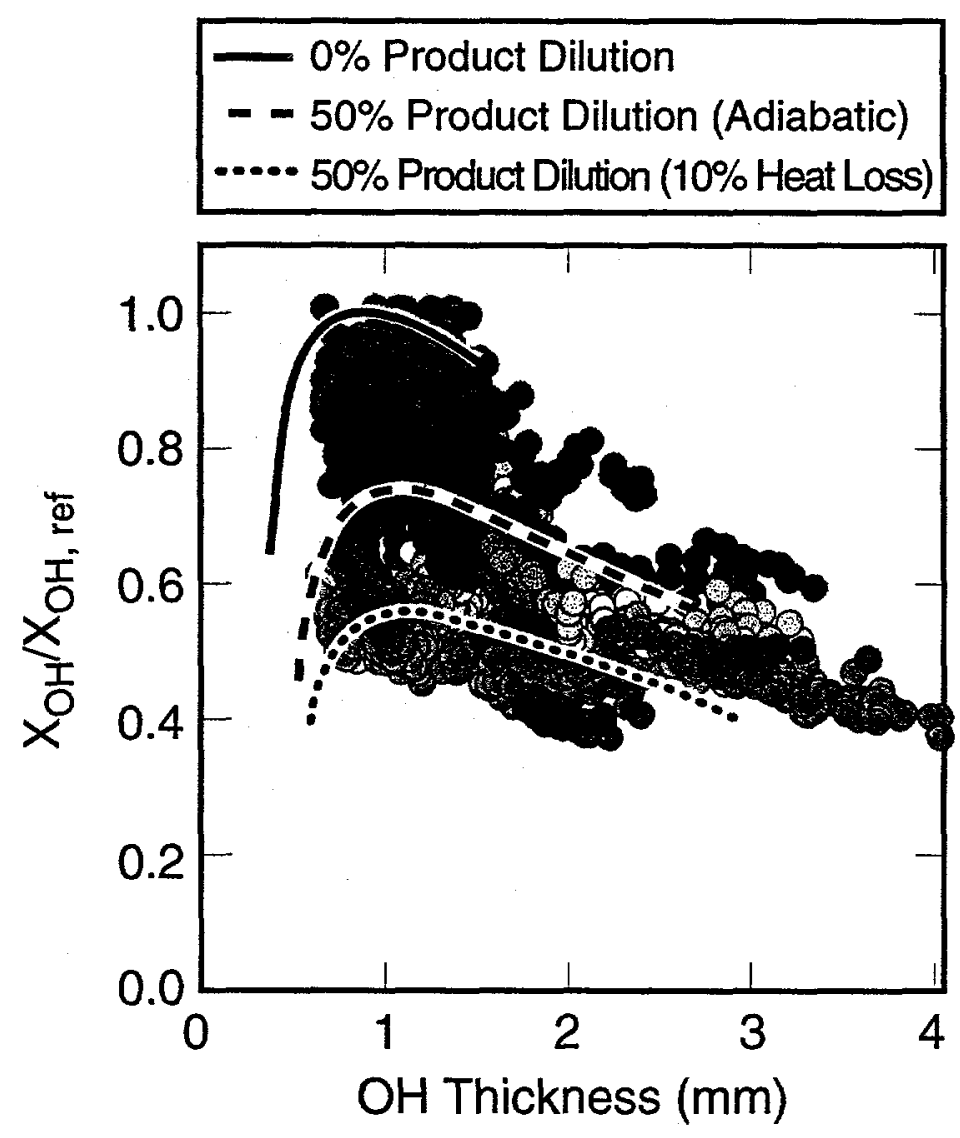

fig. 6 